\title{
Index jentik dan pupa nyamuk aedes spp di wilayah Kombos Timur kota Manado
}

\author{
${ }^{1}$ Amaliah S. Yustin \\ ${ }^{2}$ Angle Sorisi \\ ${ }^{2}$ Victor D. Pijoh.
}

\author{
${ }^{1}$ Kandidat Skripsi Fakultas Kedokteran Universitas Sam Ratulangi Manado \\ ${ }^{2}$ Bagian Parasitologi Fakultas Kedokteran Universitas Sam Ratulangi Manado \\ Email: amalia_syadzwina@yahoo.com
}

\begin{abstract}
Larvae and pupae of Aedes spp outgrowth of the egg stage to become a mosquito that may contribute to the spread of Dengue Hemorrhagic Fever (DHF) with two vectors that transmit dengue, the Aedes aegypty and Aedes albopictus. Data from Manado City Health Department in 2013 recorded 29 cases of dengue fever in the region Kombos. In 2014, the number of cases found that 29 cases with one death rate from 517 across the 2015 dengue cases and found 13 cases of dengue. Data from Kombos Health Center states in 2015 reported the number of dengue patients range from three people. The purpose of this research is to know the index larvae and pupae and know the type of larvae and pupae Aedes spp that located in the area of East Kombos. This study used a descriptive research with time from September to December 2016. The primary data in the form of case data in Puskesmas Kombos East. The research took place in East Kombos and used parasitology laboratory medical faculty of the University of Sam Ratulangi. The population is the entire of larvae and pupae which is in the eastern Kombos and samples were taken from 100 homes of the entire homes at that location. Based on the index research larvae and pupae in the east Kombos obtained House Index (HI) 46\%, Container Index (CI) 28.6\%, Breteau Index (BI) $62 \%$ pupae Index (PI) with $13 \%$ so region of east Kombos including the high degree of density and the potential occurrence of dengue. The most type larvae and pupae were found namely Aedes aegypty.
\end{abstract}

Keywords: index larvae and pupae, aedes spp

\begin{abstract}
Abstrak: Jentik dan pupa nyamuk Aedes spp merupakan perkembangan dari stadium telur hingga menjadi nyamuk yang dapat berperan terhadap penyebaran penyakit Demam Berdarah Dengue (DBD) dengan dua vektor yang menularkan dengue, yaitu Aedes aegypti dan Aedes albopictus. Data dari Dinas Kesehatan Kota Manado tahun 2013 tercatat 29 kasus DBD di wilayah Kombos. Tahun 2014, jumlah kasus didapatkan 29 kasus dengan angka kematian satu dari 517 kasus DBD dan tahun 2015 didapatkan 13 kasus DBD. Dari data Puskesmas Kombos menyatakan bahwa pada tahun 2015 dilaporkan jumlah pasien demam berdarah berkisar tiga orang. Tujuan penelitian ini yaitu mengetahui index jentik dan pupa serta mengetahui jenis jentik dan pupa Aedes spp yang terdapat di daerah Kombos Timur. Tujuan penelitian ini yaitu mengetahui index jentik dan pupa serta mengetahui jenis jentik dan pupa Aedes spp yang terdapat di daerah Kombos Timur. Penelitian ini menggunakan jenis penelitian deskriptif dengan waktu penelitian yaitu September-Desember 2016. Pengambilan data primer berupa data kasus di Puskesmas Kombos Timur dan wilayah penelitian bertempat di Kombos Timur seta di Laboratorium parasitologi fakultas kedokteran Universitas Sam Ratulangi dengan populasi seluruh jentik dan pupa yang berada di Kombos Timur dan sampel yang diambil yaitu 100 rumah.Berdasarkan hasil penelitian index jentik dan pupa di wilayah Kombos Tmiur didapatkan House Index (HI) 46\%, Container Index (CI) 28,6\%, Breteau Index (BI) 62\% Pupa Index (PI) dengan angka 13\%
\end{abstract}


sehingga wilayah Kombos Timur termasuk pada derajat kepadatan yang tinggi dan berpotensi terjadinya DBD. Jenis jentik dan pupa yang didapatkan yang terbanyak yaitu Aedes aegypty.

Kata kunci: index jentik dan pupa, aedes spp

Jentik dan pupa nyamuk Aedes spp merupakan perkembangan dari stadium telur hingga menjadi nyamuk yang dapat berperan terhadap penyebaran penyakit Demam Berdarah Dengue (DBD). ${ }^{1}$ Nyamuk Aedes spp adalah spesies nyamuk tropis dan subtropis di seluruh dunia dalam garis lintang $35^{\circ} \mathrm{LU}$ dan $35^{\circ} \mathrm{LS}$. Namanya diperoleh dari perkataan Yunani yaitu aedes, yaitu "tidak menyenangkan" karena nyamuk ini menyebarkan beberapa penyakit berbahaya seperti demam berdarah dan demam kuning. ${ }^{2}$ Di Indonesia terdapat dua vektor yang menularkan dengue, yaitu Aedes aegypti dan Aedes albopictus. ${ }^{3}$

Demam berdarah dengue merupakan penyakit demam akut. ${ }^{4}$ Penyakit ini masuk ke dalam Indonesia melalui pelabuhan Surabaya pada tahun 1968 dan pada tahun 1980 sudah menyebar ke seluruh Indonesia. Vektor utama DBD yaitu nyamuk yang dikenal dengan nama Aedes aegypty dan vector potensialnya yaitu Aedes albopticus. ${ }^{5}$

Di Indonesia, data Kementrian Kesehatan RI mencatat kasus DBD secara nasional pada tahun 2009 mencapai sekitar 150 ribu kasus. Kasus kematian didapatkan tidak banyak berubah dari $0,89 \%$ pada tahun 2009 menjadi $0,87 \%$ pada tahun 2010. Hal ini berarti terdapat 1.420 korban meninggal akibat DBD pada tahun 2009 dan sekitar 1.317 korban meninggal pada tahun berikutnya. ${ }^{6}$

Pada tahun 2011 kasus DBD sebesar 65.725 dengan angka insiden 27,67 per 100.000 penduduk dengan jumlah kematian 595 kasus dan di tahun 2012 mencapai 37,11 per 100.000 dengan jumlah kasus meninggal sebesar 816 kasus (Kemenkes RI, 2013). Depkes RI mencatat, di Indonesia pada tahun 2013 dengan jumlah 112.511 orang dan jumlah kasus meninggal sebanyak 871 penderita, dan di tahun 2014 sebanyak 71.668 orang dan diantaranya meninggal dunia.

Berdasarkan sumber yang diperoleh dari Dinas Kesehatan Kota Manado, pada tahun 2013 tercatat bahwa angka kasus demam berdarah terjadi di semua kecamatan kota Manado yaitu salah satunya di wilayah Kombos dengan jumlah 29 kasus. $^{7}$ Tahun 2014, jumlah kasus didapatkan 29 kasus dengan angka kematian 1 dari 18 kasus kematian dan dari 517 seluruh kasus DBD $^{8}$ dan tahun 2015 didapatkan 13 kasus DBD. ${ }^{9}$

Dari data Puskesmas Kombos menyatakan bahwa pada tahun 2015 dilaporkan jumlah pasien demam berdarah berkisar tiga orang di Kombos Timur.

Dari kasus-kasus yang tercatat, maka didapatkan masih maraknya kasus demam berdarah walau terjadi penurunan tiap tahunnya. Karena adanya kasus DBD pada daerah Kombos Timur Kota Manado, perlunya diteliti index jentik dan pupa serta memantau secara langsung di daerah Kombos Timur untuk mengetahui tingkat kepadatan serta mengidentifikasikan jenis jentik dan pupa didaerah tersebut.

\section{METODE PENELITIAN}

Penelitian ini menggunakan jenis penelitian deskriptif. Penelitian dilakukan di Kelurahan Kombos Timur Kota Manado pada bulan September-Desember 2016. Pengambilan data primer berupa data kasus di Puskesmas Kombos Timur dan wilayah penelitian bertempat di Kombos Timur seta di Laboratorium parasitologi fakultas kedokteran Universitas Sam Ratulangi.

Pengambilan sampel yaitu 100 rumah yang diambil dari seluruh populasi jentik dan pupa di wilayah Kombos Timur.

Definisi Operasional yaitu berupa jentik dan pupa nyamuk Aedes spp di wilayah Kombos Timur dan perhitungan index yaitu House Index (HI), Container 
Index (CI), Breteau Index (BI), Pupa Index (PI) dan Angka bebas Jentik (ABJ) berdasarkan data-data yang didapatkan di tiap rumah diwilayah Kombos Timur kemudian dimasukkan di density figure. ${ }^{17}$

\section{HASIL PENELITIAN}

Berdasarkan proses penelitian melalui kunjungan di tiap rumah dan dilakukan observasi dan pengamatan di laboratorium. Pehitungan dilakukan berdasarkan rumus index, jumlah, jenis, bahan di tiap container positif jentik dan pupa baik didalam maupun diluar rumah dan diidentifikasikan jenis Aedes spp kemudian ditabulasi.

Tabel 1. Persentase rumah yang positif jentik dan pupa

\begin{tabular}{crc}
\hline Rumah & Jumlah & \% \\
\hline+ & 46 & $46 \%$ \\
- & 54 & $54 \%$ \\
Total & 100 & $100 \%$ \\
\hline
\end{tabular}

Keterangan:

$+\quad$ : Rumah yang positif jentik dan pupa

- $\quad$ : Rumah yang negatif jentik dan pupa

Tabel 2. Persentase container yang positif jentik dan pupa

\begin{tabular}{lccccc}
\hline \multicolumn{1}{c}{$\begin{array}{c}\text { Container } \\
\text { (TPA) }\end{array}$} & $\begin{array}{c}\text { Jumlah } \\
(\mathbf{N})\end{array}$ & $\begin{array}{c}\text { (+) Jentik } \\
\text { TPA (+) }\end{array}$ & $\begin{array}{c}\text { (+) Pupa } \\
\text { Jentik }\end{array}$ & $\begin{array}{c}\%(+) \\
\text { Pupa }\end{array}$ \\
\hline Bak mandi & 32 & 9 & $3.44 \%$ & 2 & $0.76 \%$ \\
Drum & 27 & 12 & $4.58 \%$ & 2 & $0.76 \%$ \\
Tempayan & 60 & 5 & $1.91 \%$ & 3 & $1.15 \%$ \\
Ember & 127 & 27 & $10.31 \%$ & 6 & $2.29 \%$ \\
NON TPA & & 2 & $0.76 \%$ & 0 & $0.00 \%$ \\
Kaleng bekas & 2 & 4 & $1.53 \%$ & 0 & $0.00 \%$ \\
Ban bekas & 7 & 1 & $0.38 \%$ & 0 & $0.00 \%$ \\
Gelas/Botol & 1 & 1 & $0.38 \%$ & 0 & $0.00 \%$ \\
$\begin{array}{l}\text { Bekas } \\
\text { Vas/Pot bunga }\end{array}$ & 1 & 0 & $0.00 \%$ & 0 & $0.00 \%$ \\
$\begin{array}{l}\text { Kolam/ } \\
\text { Aquarium }\end{array}$ & 1 & & & & \\
NON TPA LAIN & & 0 & $0.00 \%$ & 0 & $0.00 \%$ \\
$\begin{array}{l}\text { Talang air } \\
\text { Tempat minum }\end{array}$ & 2 & 1 & $0.38 \%$ & 0 & $0.00 \%$ \\
$\quad$ burung & & & & & \\
HABITAT ALAMI & & 0 & $0.00 \%$ & 0 & $0.00 \%$ \\
$\begin{array}{l}\text { Pelepah daun } \\
\text { TOTAL }\end{array}$ & 1 & 62 & $23,7 \%$ & 13 & $4,96 \%$ \\
\hline
\end{tabular}

Tabel 3. Jumlah jenis jentik dan pupa Aedes spp

\begin{tabular}{lcc}
\hline JENIS Aedes Spp & JENTIK & PUPA \\
\hline Aedes Aegypty & 56 & 11 \\
Aedes Albopticus & 6 & 2 \\
\hline
\end{tabular}


Tabel 4. Persentase bahan container yang positif jentik dan pupa

\begin{tabular}{cccccc}
\hline Bahan & Jumlah (N) & (+) Jentik & $\begin{array}{l}\text { \% (+) } \\
\text { Jentik }\end{array}$ & $\begin{array}{c}(+) \\
\text { Pupa }\end{array}$ & $\begin{array}{c}\text { \% (+) } \\
\text { Pupa }\end{array}$ \\
\hline Semen & 10 & 2 & $0.8 \%$ & 1 & $0.38 \%$ \\
Tanah Liat & 1 & 0 & $0.00 \%$ & 0 & $0.00 \%$ \\
Plastik & 208 & 44 & $16.8 \%$ & 11 & $4.20 \%$ \\
Kaca & 2 & 1 & $0.4 \%$ & 0 & $0.00 \%$ \\
Keramik & 28 & 7 & $2.7 \%$ & 1 & $0,38 \%$ \\
Karet & 7 & 4 & $1.5 \%$ & 0 & $0.00 \%$ \\
Alumunium & 5 & 4 & $1.5 \%$ & 0 & $0.00 \%$ \\
Daun & 1 & 0 & $0.00 \%$ & 0 & $0.00 \%$ \\
Total & 262 & 62 & $23,7 \%$ & 13 & $4,96 \%$ \\
\hline
\end{tabular}

Tabel 5. Jumlah container tertutup/ terbuka yang positif jentik dan pupa

\begin{tabular}{lcc}
\hline Container & (+) Jentik & (+) Pupa \\
\hline Tertutup & 15 & 4 \\
Terbuka & 47 & 9 \\
Total & 62 & 13 \\
\hline
\end{tabular}

Tabel 6. Letak/ tempat container yang positif jentik dan pupa

\begin{tabular}{lcc}
\hline $\begin{array}{l}\text { Letak/Tempat } \\
\text { (Container) }\end{array}$ & (+) Jentik & (+) Pupa \\
\hline Dalam & 29 & 10 \\
Luar & 33 & 3 \\
Total & 62 & 13 \\
\hline
\end{tabular}

Tabel. 7 Jangka waktu pengurasan container dalm 1 Minggu yang positif jentik dan pupa

\begin{tabular}{ccc}
\hline $\begin{array}{c}\text { Dikuras 1 minggu } \\
\text { terakhir }\end{array}$ & (+) Jentik & (+) Pupa \\
\hline Ya & 43 & 10 \\
Tidak & 19 & 3 \\
Total & 62 & 13 \\
\hline
\end{tabular}

Tabel 8. Persentase Index (House Index, Container Index, Breteau Index, Pupa Index)

\begin{tabular}{ccc}
\hline & INDEX & HASIL \\
\hline & HI & $46 \%$ \\
& CI & $28,6 \%$ \\
& BI & $62 \%$ \\
& PI & $13 \%$ \\
& ABJ & $54 \%$ \\
Keterangan: & HI (House Index) \\
& CI (Container Index) \\
& BI (Breteau Index) \\
& PI (Pupa Index)
\end{tabular}

\section{BAHASAN}

Dari proses penelitian yang telah dilakukan, dari tabel 1 didapatkan rumah yang positif jentik yaitu 46 rumah dari 100 rumah dengan presentase $46 \%$. Hasil rumah yang negatif didapatkan 54 rumah dari 100 rumah dengan presentase $56 \%$.

Berbeda dengan penelitian yang dilakukan oleh Lini Ariva dan Katharina Oginawati (2013) di wilayah Cicadas, Bandung yaitu index untuk jentik 53 rumah, didapatkan bahwa terdapat 34 rumah yang positif jentik. ${ }^{18}$

Hal ini menunjukkan, selisih berbeda jauh dari penelitian dilakukan di wilayah Kombos Timur, Manado dan terbilang lebih tinggi dengan angka 54 rumah yang bebas jentik dari 100 dibandingkan dengan penelitian di wilayah Cicadas, Bandung dengan angka rumah bebas jentik yaitu 19 rumah. Hal ini dapat terjadi karena kemungkinan pada daerah Cicadas, Kota Bandung dengan lingkungan yang kurang menjadi perkumpulan nyamuk-nyamuk didaerah tersebut.

Pada Tabel 2 dari hasil perhitungan container yang positif pupa dan jentik, didapatkan jumlah dengan kepadatan jentik tertinggi terdapat pada jenis container ember dengan jumlah 27 dari 127 total container ember dan dari total 262 seluruh container yang diperiksa dengan presentase $10,31 \%$ dari jumlah seluruh container yang diperiksa (28.6\%) dan jumlah container yang positif pupa tertinggi didapatkan pada ember dengan jumlah 6 dari 127 total container ember dan 262 container yang diperiksa dengan presentase 2,29\% dari 
$28.6 \%$ jumlah seluruh container yang diperiksa.

Hal ini berbeda dengan penelitian yang dilakukan oleh Sang G. Purnama dan Tri Baskoro (2012) yaitu tempat penampungan air (TPA) paling banyak jentik yaitu bak mandi $(29,27 \%) .{ }^{19}$ Begitu pun dengan penelitian Shinta dan Supratman Sukowati (2013) Di wilayah DKI Jakarta jenis TPA positif pupa dengan persentase terbesar ditemukan pupa adalah di bak mandi $(34,23 \%) .{ }^{20}$ Hal ini melihatkan bahwa jentik dan pupa dapat terjadi dimana saja tetapi hal yang membedakan container yang banyak terdapat pupa hal ini disebabkan perbedaaannya tingkat kebersihan container yang diperiksa.

Identifikasi dari masing-masing pupa dan jentik yang telah di ambil dari proses penelitian yang telah dilakukan tertera pada tabel 3 didapatkan jentik Aedes aegypty berjumlah 56 dan jentik Aedes albopticus berjumlah 6 dari 62 seluruh jumlah jentik yang diperiksa. Jumlah pupa Aedes aegypty didapatkan 11 dan pupa Aedes albopticus didapatkan 2 dari 13 semua jenis pupa yang diperiksa.

Hal ini menunjukkan masih banyaknya di setiap rumah dengan jentik dan pupa Aedes aegypty wilayah Kombos Timur dibandingkan jentik dan pupa Aedes albopticus dikarenakan pemukiman pada wilayah Kombos Timur, kondisi lingkungan perumahan yang tertata dengan kondisi air yang bersih dan kurang terdapatnya kebun-kebun di tiap rumah sesuai teori yang di kemukakan oleh Irianto K (2013).

Pada Tabel 4, bahan container yang positif jentik yaitu terdapat jumlah tertinggi pada container berbahan plastik dengan angka 44 dari 208 container plastik yang didapat dan dari 262 seluruh jumlah bahan container yang diperiksa dengan presentase $16.8 \%$ dari $28.6 \%$ seluruh jumlah bahan container. Jumlah bahan container yang positif pupa tertinggi di dapatkan pada container berbahan plastik dengan angka 11 dari 208 container plastik yang didapat dan dari 262 container yang diperiksa dengan presentase $5,77 \%$ dari $4.20 \%$ seluruh jumlah bahan container.

Hasil penelitian yang didapat berbeda dengan penelitian Wanti dan Menofeltus Darman (2014) dengan di Kelurahan Alak, Kota Kupang dengan angka mencapai $(47,7 \%)$ pada container berbahan besi. ${ }^{21}$

Perbedaan ini didapatkan saat penelitian yang dilakukan, terdapat banyaknya container berbahan plastik disetiap rumah di bandingkan bahan yang lainnya yang rawan menjadi tempat perindukan nyamuk.

Pada tabel 5, Jumlah container tertutup yang positif jentik didapatkan 15 jentik dan yang terbuka didapatkan 47 dari 62 container yang positif jentik. Jumlah container tertutup yang positif pupa didapatkan 4 pupa dan yang terbuka didapatkan 9 dari 13 container yang positif pupa. Penelitian ini sama halnya dengan yang dilakukan Wanti dan Menofeltus Darman (2014) dengan di Kelurahan Alak, Kota Kupang dengan kondisi container yang terbanyak adalah yang terbuka. ${ }^{21}$

Dengan kondisi container yang terbuka atau tidak tertutup rapat memudahkan nyamuk keluar masuk container dan bertelur di container tersebut sebagai sarang tempat perkembangbiakan nyamuk.

Didapatkan pula pada container yang tertutup dikarenakan mungkin pada tempat container tersebut tidak di tutup rapat atau terbuka lama sebelum ditutup rapat.

Pada tabel 6, letak container yang positif jentik didapatkan tertingggi yaitu di dalam rumah dengan angka mencapai 33 dari 62 jumlah container positif jentik yang diperiksa. Letak container yang positif pupa didapatkan tertingggi berada di dalam rumah dengan angka 10 dari 13 jumlah container positif jentik yang diperiksa.

Sama halnya dengan penelitian yang dilakukan oleh Wanti dan Menofeltus Darman (2014) dengan daerah yang endemis yaitu di Kelurahan Alak, Kota Kupang dengan container yang terletak di luar rumah dengan persentase $62,8 \% .^{21} \mathrm{Hal}$ ini menunjukkan, pada saat penelitian dilakukan, container dekat dengan kebunkebun dan pohon maupun dengan lingkungan lembab yang lebih banyak menjadi tempat perindukan nyamuk. ${ }^{2}$ 
Pengurasan setiap container di tiap rumah yang positif jentik yang tertera pada tabel 7 didapatkan dengan jumlah 43 dari 62 container di tiap rumah yang positif jentik sedangkan rumah yang containernya tidak di kuras terdapat 19 container yang positif jentik. Pengurasan setiap container di tiap rumah yang positif pupa didapatkan dengan jumlah 10 dari 13 container di tiap rumah yang positif pupa sedangkan rumah yang containernya tidak di kuras terdapat 3 container yang positif pupa. Ini berarti bahwa jentik dan pupa lebih suka pada container yang di kuras setiap minggunya dibandingkan yang tidak. ${ }^{15}$

Berdasarkan data dan perhitungan pada Tabel 8 di dapatkan untuk jentik yaitu HI $46 \%$, CI $28,6 \%$, BI $62 \%$. Ini berarti berdasarkan density figure pada tabel 1, didapatkan HI dan BI berada pada derajat 6 sedangkan CI berada pada derajat 7 yang artinya terdapat kepadatan jentik Aedes spp yang tinggi. Untuk pupa didapatkan index dengan PI 13\%. ABJ (Angka Bebas Jentik) didapatkan 54\% dari 100 rumah. Ini berarti didapatkannya $A B J$ yang rendah dari nilai nasional karena pada wilayah tersebut terdapat $\mathrm{ABJ}<95 \%$ untuk daerah yang berpotensial. $^{22}$

Hal ini berarti penelitian yang telah dilakukan berbeda dengan penelitian yang dilakukan oleh Lini Ariva dan Katharina Oginawati (2013) di wilayah Cicadas, Bandung yaitu index untuk jentik yaitu HI $22,22 \%$, CI $12,84 \%$ dan BI 27,45 dengan derajat sedang, tetapi nilai angka bebas jentik sama halnya dengan penelitian yang dilakukan yaitu termasuk kategori Angka Bebas Jentik (ABJ) rendah yaitu (ABJ) sebesar $77,78 \%$ dari nilai nasional yang ditetapkan. ${ }^{18}$ Perbedaan ini didapatkan disaat melakukan penelitian, lingkungan pada wilayah Kombos Timur yang lebih memadai untuk perindukan nyamuk yang lebih banyak sehingga terdapatnya kepadatan nyamuk Aedes spp yang tinggi.

\section{SIMPULAN}

Dari proses dan hasil penelitian yang dilakukan di wilayah Kombos Timur didapatkan HI 46\%, CI 28,6\%, BI 62\% dan disimpulkan bahwa kepadatan jentik dan pupa berada pada derajat kepadatan yang tinggi. Didapatkan PI dengan angka 13\% dan ABJ (Angka Bebas Jentik) 54\% dapat disimpulkan bahwa daerah Kombos Timur merupakan wilayah yang berpotensial terjadinya DBD.

Jenis jentik dan pupa yang didapatkan yang terbanyak yaitu Aedes aegypty.

\section{SARAN}

Diharapkan masyarakat sekitar wilayah Kombos Timur lebih meningkatkan kebersihan di setiap container baik didalam maupun diluar rumah.

\section{UCAPAN TERIMA KASIH}

Ucapan terima kasih kami sampaikan kepada Kepala Bagian Parasitologi Fakultas Kedokteran Unsrat yang telah memberi kesempatan kepada peneliti melakukan penelitian ini. Kepada Kepala Lurah Kombos Timur yang telah memberikan izin untuk melakukan penelitian di wilayah Kombos Timur serta Kepala Puskesmas yang telah mendukung jalannya penelitian di lapangan.

\section{DAFTAR PUSTAKA}

1. Medicalogy. Jangan Sepelekan Jentik Nyamuk Saat Musim Hujan. Available from: http//www.medicalogi.com.

2. Universitas Sumatra Utara. Tinjauan Nyamuk Aedes spp. Available from: $\mathrm{http} / w w w$. repository.usu.ac.id

3. Universitas Sumatra Utara. Karakteristik Nyamuk Aedes spp. Available from: http/www.repository.usu.ac.id/bitstrea m/123456789/35240/4/Chapter\%20ll. pdf.html

4. Irianto K. Parasitologi kedokteran. Bandung: ALFABETA, cv; 2013. h. 168-73.

5. Safar R. Parasitologi Kedokteran: Protozooologi, Helmitologi, Entomologi. Bandung: YRAMA WIDYA, CV.; 2009. h. 254-55.

6. Rahayu F.D, Ustiawan A. Identifikasi Aedes Aegypty dan Aedes Albopticus. BALABA. 2013; 9: 7

7. Dinas Kesehatan Kota Manado. Buku Pofil kesehatan Kota Manado.2013. 
8. Dinas Kesehatan Kota Manado. Buku Pofil kesehatan Kota Manado.2014.

9. Dinas Kesehatan Kota Manado. Buku Pofil kesehatan Kota Manado.2015.

10. Susanto I, Ismid I.S, Sjarifuddin P.K, Sungkar S. Parasitologi Kedokteran. Edisi ke-4.Jakarta: Badan Penerbit FKUI; 2013. h. 265.

11.L.A Prianto J, P.U Tjahaya, Darmawanto. Atlas Parasitologi kedokteran. Jakarta: Gramedia Pustaka Utama, PT; 2008. h. 183- 86

12. Cutwa M. M, O’Meara G.F, Cutwa M. M, O'Meara G.F, Photograpic Guide To Common Mosquitoes Of Florida. University of Florida-IFAS. Florida Medical Entomology Laboratory

13. CVBD (Companion Vector-Borne Disease). General Morphology. Available from: www.cvbd.org

14.SC Johnson. What is the Aedes Aegypty Mosquito. Available from: $\mathrm{http} / /$ www.scjohnson.com

15. Irianto K. Parasitologi Berbagai Penyakit yang Mempengaruhi Kesehatan Manusia. Bandung: cv; 2013. h. 20305.

16. World Health Organization. Dengue Control: vector surveillance. 2016.
Availablefrom:http://www.who.int/den guecontrol/monitoring/vector_surveilla nce/en.html.

17.Queensland government. Queensland: Dengue Management Plan (DMP) 2010-2015. 2011. h. 45.

18. Ariva L, Oginawati K. Identifikasi Density Figure Dan Pengendalian Vektor Demam Berdarah Pada Kelurahan Cicadas Bandung. 2013.

19.Purnama S.G, Baskoro T. Maya Index Dan Kepadatan Larva Aedes aegypti Terhadap Infeksi Dengue. 2012.

20.Shinta, Sukowati S. Penggunaan Metode Survei Pupa Untuk Memprediksi Risiko Penularan Demam Berdarah Dengue Di Lima Wilayah Endemis Di DKI Jakarta. Media Litbangkes. 2013; 23 (1).

21.Wanti, Darman M. Tempat Penampungan Air dan Kepadatan Jentik Aedes sp. di daerah Endemis dan Bebas Demam Berdarah Dengue.Jurnal Kesehatan Masyarakat Nasional.2014; 9 (2).

22.Surveilans epidemiologi. Fakultas Kesehatan Masyarakat. Available from: fk.uad.ac.id. 